\title{
Incidence of and risk factors for hungry bone syndrome in 84 patients with secondary hyperparathyroidism
}

This article was published in the following Dove Press journal: International Journal of Nephrology and Renovascular Disease 5 July 2013

Number of times this article has been viewed

\author{
Joerg Latus' \\ Meike Roesel' \\ Peter Fritz ${ }^{2}$ \\ Niko Braun' \\ Christoph Ulmer ${ }^{3}$ \\ Wolfgang Steurer \\ Dagmar Biegger ${ }^{4}$ \\ M Dominik Alscher ${ }^{1}$ \\ Martin Kimmel' \\ 'Department of Internal Medicine, \\ Division of Nephrology, Robert \\ Bosch Hospital, Stuttgart, Germany; \\ ${ }^{2}$ Department of Diagnostic Medicine, \\ Robert Bosch Hospital, Stuttgart, \\ Germany; ${ }^{3}$ Department of Surgery, \\ Robert Bosch Hospital, Stuttgart, \\ Germany; ${ }^{4}$ Margarete Fischer-Bosch \\ Institute of Clinical Pharmacology, \\ University of Tuebingen, Stuttgart, \\ Germany
}

Introduction: Secondary hyperparathyroidism develops in nearly all patients with end-stage renal disease. Parathyroidectomy is often performed when medical therapy fails. The most common postoperative complication, hungry bone syndrome (HBS), requires early recognition and treatment.

Materials and methods: A total of 84 patients who underwent parathyroidectomy because of secondary hyperparathyroidism were investigated. Detailed analysis of laboratory parameters (calcium, phosphate, parathyroid hormone, hemoglobin, and urea levels) and baseline characteristics (age at time of surgery, duration of renal replacement therapy, and medication) was performed to detect preoperative predictors for the development of HBS.

Results: Average overall follow-up of the cohort was 4.7 years. Within this time frame, 13 of 84 patients had to undergo a second surgery because of recurrent disease, and HBS occurred in $51.2 \%$. Only decreased preoperative calcium levels and younger age at time of surgery were significant predictors of HBS. Minimal levels of calcium were detected 3 weeks after surgery. Preoperative vitamin D therapy could not prevent HBS and could not shorten the duration of intravenous calcium supplementation.

Conclusion: HBS is a very common complication after parathyroidectomy. Younger patients and patients with low preoperative calcium levels were at higher risk for the development of HBS. Remarkably, preoperative vitamin D therapy could not prevent HBS and had no impact on the length of intravenous calcium supplementation. Intensive monitoring of calcium levels must be performed for at least 3 weeks after surgery.

Keywords: secondary hyperparathyroidism, parathyroidectomy, hungry bone syndrome

\section{Introduction}

In patients with chronic kidney disease (CKD), secondary hyperparathyroidism (sHPT) is a very common complication; sHPT will ultimately develop in approximately all patients with end-stage renal disease (ESRD). ${ }^{1}$ Three major factors influence stimulation of the parathyroid gland in patients with chronic renal failure: diminished 1,25dihydroxyvitamin D levels, hypocalcemia, and hyperphosphatemia. Therefore, medical management of sHPT in patients with CKD includes the use of phosphate binders, active vitamin D analogs, and/or calcimimetics., ${ }^{2,3}$ Management of sHPT is based on recommendations from the National Kidney Foundation Kidney Disease Outcomes Quality Initiative for the evaluation and management of CKD with mineral and bone disorder. ${ }^{4}$ The number of patients requiring parathyroidectomy because of severe sHPT ranges from $2.6 \%-40 \%$ in the end-stage renal disease population. ${ }^{5-9}$ In patients with severe hyperparathyroidism and medical treatment failure, parathyroidectomy is the 
safest treatment option. Efficacy rates are favorable in the hands of an experienced surgeon. ${ }^{10,11}$

Hungry bone syndrome (HBS) occurs in up to $95 \%$ of patients and is the most common complication presenting immediately after parathyroidectomy. ${ }^{1,5,11,12}$ HBS is characterized by a precipitous postoperative decrease in the plasma concentrations of calcium and phosphorus causing tetany, seizures, cardiac arrhythmias, muscle cramps, weakness, and headache. ${ }^{5,13}$ Preoperative risk factors for the development of HBS are controversial in the current literature. ${ }^{1,5,14}$

In everyday clinical practice, it would be helpful to predict which subpopulation of patients undergoing parathyroidectomy because of severe sHPT might be at high risk for HBS. Therefore, we analyzed data from a large cohort of patients who underwent parathyroidectomy because of severe SHPT to detect preoperative predictors for the development of HBS.

\section{Materials and methods}

\section{Patients}

Our present study included 84 patients who underwent parathyroidectomy because of sHPT between January 1, 1995, and April 30, 2005, in our hospital.

Data collection included patient sex; age at the time of surgery; and operative-, laboratory-, medication-, and dialysis-related data.

The following laboratory parameters were evaluated in all patients from the medical charts preoperative and, for multiple time points, postoperatively: hemoglobin, urea, serum creatinine, calcium, phosphate, and intact parathormone.

In addition, we collected detailed information about medication. Daily doses of vitamin D, phosphate-binding drugs (sevelamer hydrochloride, calcium acetate, and algeldrate), and antihypertensive drugs were obtained preoperatively and postoperatively.

This study was performed in accordance with the principles of the Declaration of Helsinki and was approved by the local ethics committee of the University of Tuebingen.

\section{Diagnosis}

All patients with the diagnosis of sHPT were receiving renal replacement therapy (hemodialysis or peritoneal dialysis) or had a functioning transplant. The diagnosis of sHPT was made according to the National Kidney Foundation Kidney Disease Outcomes Quality Initiative clinical practice guidelines for bone metabolism and disease in CKD. ${ }^{4}$

\section{Surgical procedure}

Parathyroidectomy was performed in patients with symptomatic sHPT that was refractory to medical therapy. All patients underwent bilateral neck exploration with an attempt to identify all parathyroid glands. When four or more glands could be detected at the time of surgery, total parathyroidectomy with or without forearm autotransplantation or subtotal parathyroidectomy was performed at the discretion of the surgeon. If fewer than four glands were detected, all other identifiable parathyroid glands were removed. In this setting, thymectomy was not performed routinely.

\section{HBS}

HBS is defined as the requirement of intravenous calcium supplementation to control serum calcium levels postoperatively after parathyroidectomy, despite optimization of supportive therapy (for example, vitamin D, oral calcium supplementation). When intravenous calcium supplementation was administered to the patient, duration of supplementation was documented.

\section{Statistical analysis}

Continuous data were expressed as mean \pm standard deviation and percentages. Median with interquartile range was used where distribution was not normal. We processed all data using the software program GraphPadPrism version 5 (GraphPad Software, Inc, La Jolla, CA, USA). We made comparisons between different groups using Fisher's exact test. The level of significance was defined as $P<0.05$; a high level of significance was defined as $P<0.01$, and a highly significant level was defined as $P<0.001$.

\section{Results}

\section{Demographics, baseline characteristics, and surgical procedures}

Between January 1995 and April 2005, a total of 84 patients who underwent parathyroidectomy because of sHPT were identified in our nephrology and surgery department. During work-up of these patients, sufficient data were given in all patients.

There were 42 female and 42 male patients with a median age of 50.9 years (age range, 20-75 years). There was no predominant diagnosis concerning the underlying disease leading to chronic renal failure in these patients. Total parathyroidectomy was performed in $78(92.9 \%)$ of 84 patients with sHPT. In 74 of these patients, autotransplantation was performed. Subtotal parathyroidectomy was performed in six patients $(7.1 \%)$. 
At the time of surgery, 55 patients were receiving hemodialysis, 23 were receiving peritoneal dialysis, and six had a functioning transplant. Time from renal replacement therapy to surgery was 5.5 years (range, 1 month to 15 years), and 42 patients received vitamin D preoperatively. In our study, median follow-up time was 4.7 years after parathyroidectomy; baseline characteristics of the study population are shown in Table 1 .

\section{Postoperative course}

Parathyroid hormone (PTH) levels decreased dramatically after surgery $(136.1 \pm 81.7 \mathrm{pmol} / \mathrm{L}$ preoperatively to $4.8 \pm 7.4 \mathrm{pmol} / \mathrm{L}$ within 1 week after surgery; $P<0.0001$ ) (Figure 1). Within the first 3 years after surgery, PTH levels were

Table I Clinical data of study population

\begin{tabular}{|c|c|}
\hline Variable & sHPT \\
\hline $\bar{N}$ & 84 \\
\hline Age, years (range) ${ }^{\mathrm{a}}$ & $50.9(20-75)$ \\
\hline Female/male & $42 / 42$ \\
\hline \multicolumn{2}{|l|}{ RRT at time of surgery } \\
\hline HD & 55 \\
\hline PD & 23 \\
\hline NTx & 6 \\
\hline Duration of dialysis ${ }^{\mathrm{a}}$ & 5.5 (I month-15 years) \\
\hline Follow-up time after surgery ${ }^{a}$ & 4.7 (2 months-II years) \\
\hline \multicolumn{2}{|l|}{ Surgical procedure } \\
\hline Total parathyroidectomy & 78 \\
\hline With autotransplantation & 74 \\
\hline Without autotransplantation & 4 \\
\hline Subtotal parathyroidectomy & 6 \\
\hline \multicolumn{2}{|l|}{ Preoperative medications } \\
\hline Vitamin $D(n=45)(\mu g /$ day $)$ & $1.09 \pm 0.82$ \\
\hline \multicolumn{2}{|l|}{ Phosphate-binding drugs } \\
\hline Sevelamer $(\mathrm{n}=12)(\mathrm{mg} /$ day $)$ & $4533 \pm 2995$ \\
\hline Calcium acetate $(\mathrm{n}=26)(\mathrm{mg} /$ day $)$ & $3852 \pm 2087$ \\
\hline Algeldrate $(n=26)(\mathrm{mg} /$ day $)$ & $3554 \pm 1600$ \\
\hline \multicolumn{2}{|l|}{ Antihypertensive drugs (all mg/day) } \\
\hline ACE inhibitor $(n=16)$ & $12.1 \pm 12.3$ \\
\hline Angiotensin 2 receptor antagonist $(n=9)$ & $81.3 \pm 90.8$ \\
\hline Calcium antagonist $(\mathrm{n}=2 \mathrm{I})$ & $30.5 \pm 51.3$ \\
\hline Beta-blocker $(n=37)$ & $51.0 \pm 55.3$ \\
\hline Diuretics $(n=28)$ & $290.1 \pm 298.1$ \\
\hline $\mathrm{Hb}(\mathrm{g} / \mathrm{dL} \pm \mathrm{SD}[13-18])$ & $12.4 \pm 2.2$ \\
\hline Leukocytes (giga/L \pm SD [4.0-II.3]) & $7.3 \pm 2.8$ \\
\hline Phosphate (mmol/L [0.68-I.68]) & $1.8 \pm 0.6$ \\
\hline Calcium (mmol/L [1.90-2.70]) & $2.6 \pm 0.2$ \\
\hline PTH (pmol/L [I.I-7.3]) & $132.3 \pm 80.3$ \\
\hline Urea-N (mg/dL [10-25]) & $111.2 \pm 50.3$ \\
\hline Creatinine (mg/dL [0.5-I.4]) & $7.7 \pm 3.7$ \\
\hline
\end{tabular}

Note: anterquartile range.

Abbreviations: sHPT, secondary hyperparathyroidism; $N$, total number; RRT, renal replacement therapy; HD, hemodialysis; PD, peritoneal dialysis; NTx, transplantation; $n$, number; $\mathrm{ACE}$, angiotensin-converting enzyme; $\mathrm{Hb}$, hemoglobin; SD, standard deviation; PTH, parathyroid hormone. significantly lower compared with preoperative PTH levels (1 year: $50.0 \pm 73.2 \mathrm{pmol} / \mathrm{L} ; 2$ years: $100.8 \pm 191.4 \mathrm{pmol} / \mathrm{L}$; 3 years: $98.1 \pm 142 \mathrm{pmol} / \mathrm{L}$; all $P<0.05)$. Remarkably, PTH levels were higher 4 years after surgery compared with preoperative PTH levels $(164.0 \pm 304.6 \mathrm{pmol} / \mathrm{L}$ at 4 years after surgery; $P>0.05$ ).

Analogous with the course of PTH levels, serum calcium levels decreased postoperatively from $2.6 \pm 0.24 \mathrm{mmol} / \mathrm{L}$ to $2.1 \pm 0.26 \mathrm{mmol} / \mathrm{L}(P<0.0001)$ on postoperative day 1 . All patients undergoing surgical treatment of sHPT received a high-calcium dialysis bath on the first postoperative day. Minimal calcium levels were found 3 weeks after surgery at $1.92 \pm 0.22 \mathrm{mmol} / \mathrm{L}$ (Figure 2).

Regarding phosphate levels, there was a decrease after surgery compared with preoperative phosphate levels from $1.9 \pm 0.59 \mathrm{mmol} / \mathrm{L}$ to $1.34 \pm 0.44 \mathrm{mmol} / \mathrm{L}(P<0.0001)$, but at 1 year after parathyroidectomy, phosphate levels had already reached levels higher than baseline $(1.95 \pm 0.62 \mathrm{mmol} / \mathrm{L})$. Within the next few years after surgery, phosphate levels remained stable.

The number of patients requiring vitamin $\mathrm{D}$ increased after surgery from 42 patients to 78 patients. Analogically, daily doses of vitamin D increased from $1.09 \pm 0.82 \mu \mathrm{g}$ /day to $2.42 \pm 1.51 \mu \mathrm{g} /$ day $(P<0.01)$. Regarding long-term follow-up, the required doses of vitamin $\mathrm{D}$ decreased significantly at 1 to 6 years after surgery compared with preoperative doses (all $P<0.05$ ). Within 4 years after surgery, the number of patients requiring phosphate-binding drugs was reduced. In addition, the doses of sevelamer, calcium acetate, and algeldrate decreased within 4 years after surgery ( $P<0.05, P>0.05$, and $P>0.05$, respectively). Concerning the use of antihypertensive drugs, no differences could be detected between preoperative and postoperative doses of angiotensin-converting enzyme inhibitors $(P=0.96)$, angiotensin 2 receptor antagonists $(P=0.29)$, beta-blockers $(P=0.90)$, calcium antagonists $(P=0.86)$, and diuretics $(P=0.99)$.

Average overall follow-up in the entire group was 4.7 years. Within this time frame, 13 of 84 patients had to undergo a second surgery because of recurrent HPT. In all of these patients, total parathyroidectomy was done initially (eleven patients with autotransplantation, two patients without autotransplantation). In six patients, recurrent graft-HPT was identified as the origin of recurrent HPT, whereas in another six patients, a second neck exploration was necessary. In one patient, both recurrent graft-HPT and adenoma of the residual parathyroid gland could be detected. 


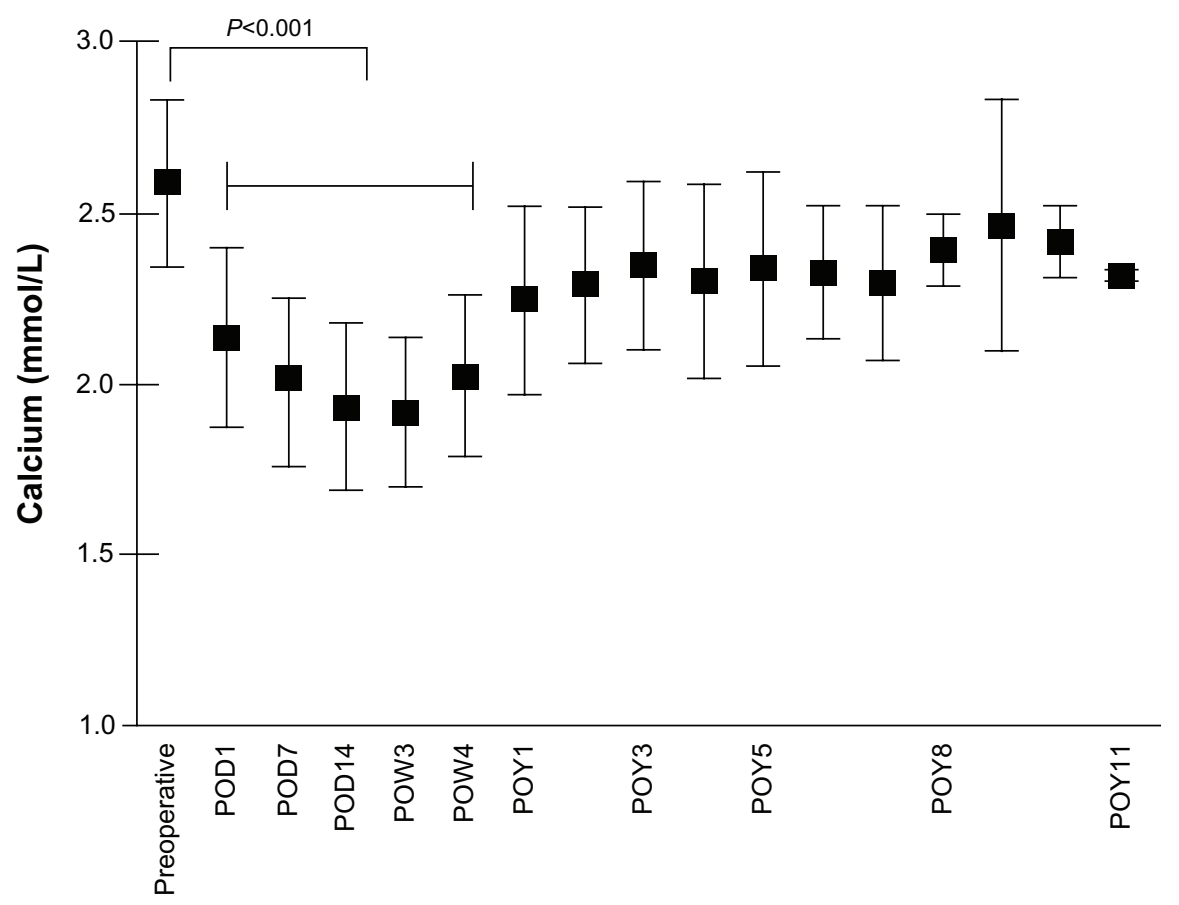

Figure I Change in serum calcium levels after parathyroidectomy.

Abbreviations: POD, postoperative day; POW, postoperative week; POY, postoperative year.

\section{HBS}

HBS was defined as the requirement of intravenous calcium supplementation to control serum calcium levels postoperatively after parathyroidectomy, despite optimization of supportive therapy (for example, vitamin D, oral calcium supplementation, dialysis calcium). Overall, HBS developed in 43 (51.2\%) of 84 patients. There were 20 female and 23 male patients.

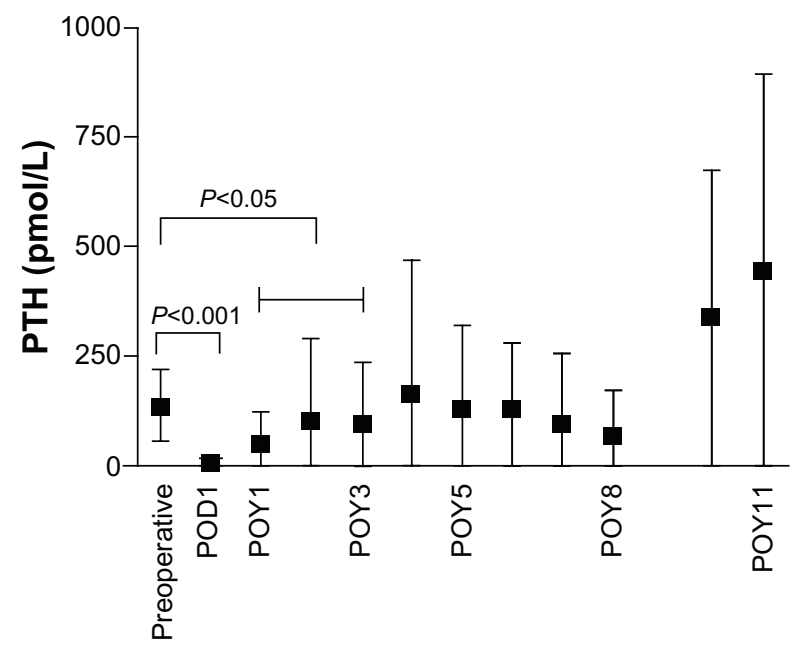

Figure 2 Change in PTH levels after parathyroidectomy.

Abbreviations: POD, postoperative day; POY, postoperative year; PTH, parathyroid hormone.
In the patients who went on to have HBS, 26 patients were treated with vitamin D preoperatively, whereas 17 patients received no vitamin $\mathrm{D}$ preoperatively. In the group of patients who did not experience HBS, 19 patients received vitamin $\mathrm{D}$, and the remaining 20 patients were not treated with vitamin D.

Within the group of patients who experienced HBS after surgery, the duration of intravenous calcium supplementation was independent of whether the patients received vitamin D before surgery (intravenous calcium supplementation, $7.8 \pm 9.0$ days versus $6.8 \pm 7.3$ days; $P=0.07$ ). In addition, no differences could be detected between serum calcium levels in the HBS group who received vitamin D therapy before surgery compared with the HBS group who did not receive vitamin $\mathrm{D}$ therapy on postoperative days 1 $(P=0.9), 7(P=0.54)$, and $14(P=0.93)$.

During work-up, several preoperative variables including calcium, phosphate, PTH, hemoglobin, and urea levels were investigated regarding prediction of the development of HBS. Furthermore, age at the time of surgery and duration of renal replacement therapy were analyzed as possible risk factors. It is interesting to note that only decreased preoperative calcium levels and younger age at the time of surgery were significant predictors of $\mathrm{HBS}$ ( $P=0.04$ and $P=0.03$, respectively). No 
other preoperative variables were significant predictors of HBS (Table 2).

\section{Discussion}

In our present study, we analyzed data from 84 patients who underwent parathyroidectomy because of refractory sHPT in a referral center in Germany. Preoperative parameters were investigated to predict which subpopulation of patients might be at high risk for the development of HBS during short-term follow-up.

Our study population consisted of 84 patients ( 42 women and $42 \mathrm{men}$ ). The mean age at the time of initiation of renal replacement therapy was 45.9 years, and time from renal replacement therapy to surgery was 5.5 years. There was no predominance of underlying kidney disease, but interestingly, only two of 84 patients had diabetic nephropathy. These baseline characteristics of our study population are in line with the results of Malberti et al, ${ }^{7}$ who found an admission age between 18 and 54 years, duration of renal replacement therapy of $66 \pm 43$ months, and nondiabetic nephropathy as underlying renal disease.

Concerning the long postoperative period, the recurrence rates of $15 \%$ during a long follow-up of 4.2 years after

Table 2 Clinical data of patients with and without HBS

\begin{tabular}{|c|c|c|}
\hline \multirow[t]{2}{*}{ Variable } & \multicolumn{2}{|c|}{ Postoperative HBS } \\
\hline & No & Yes \\
\hline $\mathrm{N}$ & 41 & 43 \\
\hline Female/male & $22 / 19$ & $20 / 23$ \\
\hline Age at surgery (years)* & $54.5 \pm 13.0$ & $47.7 \pm 15.1$ \\
\hline Duration of dialysis (months) & $57.3 \pm 43.0$ & $73.6 \pm 44.7$ \\
\hline \multicolumn{3}{|l|}{ Preoperative laboratory values } \\
\hline Calcium (mmol/L $[1.90-2.70])^{*}$ & $2.65 \pm 0.28$ & $2.54 \pm 0.20$ \\
\hline Phosphate (mmol/L [0.68-1.68]) & $1.82 \pm 0.46$ & $1.92 \pm 0.69$ \\
\hline PTH (pmol/L [I.I-7.3]) & $118.5 \pm 73.5$ & $150.2 \pm 86.1$ \\
\hline $\mathrm{Hb}(\mathrm{g} / \mathrm{dL} \pm \mathrm{SD}[13-18])$ & $12.3 \pm 2.4$ & $12.5 \pm 2.0$ \\
\hline Urea-N (mg/dL [10-25]) & $114.6 \pm 54.6$ & $117.3 \pm 44.7$ \\
\hline Vitamin D preoperatively & $21 / 41$ & $26 / 43$ \\
\hline \multicolumn{3}{|c|}{ Duration of calcium supplementation postoperatively (days) } \\
\hline \multicolumn{2}{|l|}{ With preoperative vitamin $D$ therapy } & $7.8 \pm 9.0$ \\
\hline \multicolumn{2}{|c|}{ Without preoperative vitamin D therapy } & $6.8 \pm 7.3$ \\
\hline \multicolumn{3}{|l|}{ With preoperative vitamin D therapy } \\
\hline \multicolumn{2}{|l|}{ Serum calcium POD I (I.90-2.70) } & $2.11 \pm 0.27$ \\
\hline \multicolumn{2}{|l|}{ Serum calcium POD 7 (I.90-2.70) } & $1.93 \pm 0.20$ \\
\hline \multicolumn{2}{|l|}{ Serum calcium POD I4 (I.90-2.70) } & $1.88 \pm 0.20$ \\
\hline \multicolumn{3}{|l|}{ Without preoperative vitamin D therapy } \\
\hline \multicolumn{2}{|l|}{ Serum calcium POD I (I.90-2.70) } & $2.10 \pm 0.14$ \\
\hline \multicolumn{2}{|l|}{ Serum calcium POD 7 (I.90-2.70) } & $1.97 \pm 0.25$ \\
\hline \multicolumn{2}{|l|}{ Serum calcium POD I4 (1.90-2.70) } & $1.88 \pm 0.28$ \\
\hline
\end{tabular}

Notes: $* P<0.05$.

Abbreviations: HBS, hungry bone syndrome; N, number; PTH, parathyroid hormone; $\mathrm{Hb}$, hemoglobin; SD, standard deviation; POD, postoperative day. parathyroidectomy are in line with previous reports. ${ }^{11,15,16}$ It is noteworthy that, and stays in contrast to another study, ${ }^{14}$ total parathyroidectomy with autotransplantation was performed in 78 of 84 patients in our study, and no recurrent disease was seen in the group of patients who underwent subtotal parathyroidectomy as the first surgical procedure. Up to now, no randomized trials have compared these three techniques (total parathyroidectomy with or without autotransplantation and subtotal parathyroidectomy), but most surgeons have performed subtotal parathyroidectomy or total parathyroidectomy with autoimplantation. The "procedure of choice" for the treatment of sHPT is different among surgeons. ${ }^{17,18}$ Nevertheless, both procedures seem to be extremely successful in controlling the hyperparathyroidism in short-term and long-term follow-up. ${ }^{19}$

After surgery, a rapid shift of calcium from the bloodstream to bone occurs, which is caused by abrupt removal of elevated PTH levels..$^{20,21}$ The symptoms of hypocalcemia range from mild symptoms, including weakness, to severe symptomatic hypocalcemia with seizures and cardiac arrhythmias., ${ }^{5,13}$ Postoperative hypocalcemia is a potentially life-threatening event and results in a prolonged hospital stay, including admission to intermediate or intensive care units. ${ }^{12}$ As expected, PTH levels decreased significantly postoperatively in our study population. Analogous with the course of PTH levels and in line with recent studies, ${ }^{12,22}$ serum calcium levels had decreased significantly after surgery. Nevertheless, it is noteworthy that minimal levels of calcium were detected 3 weeks after surgery, whereas a previous study stated minimal calcium levels 9 days after surgery. ${ }^{12}$ These findings underline the importance of intensive "long-term" monitoring after parathyroidectomy.

Medical management of hypocalcemia yields an increase in costs for the medical health care system. Therefore, we investigated the incidence of HBS and performed an analysis to predict which patients are at high risk for the development of HBS after parathyroidectomy. The incidence of HBS in our study $(51.2 \%)$ was above the range quoted in some reports ${ }^{11,14}$ but was equal to the results from Viaene et al. ${ }^{12}$ Comparisons among the different studies seem to be impossible because of varying definitions, as well as different presurgical and postsurgical protocols including medications and investigated parameters. ${ }^{1,2,11,12,14}$ We defined HBS as the requirement for intravenous calcium supplementation to control serum calcium levels postoperatively.

In a first step, we attempted to detect preoperative parameters, which are associated with an increased risk for the development of HBS. Parameters included calcium, 
phosphate, PTH, hemoglobin, and urea levels. In addition, age at the time of surgery and duration of renal replacement therapy were analyzed as predictors for HBS. Interestingly, only lower preoperative calcium levels and younger age at the time of surgery were significant predictors of HBS. Age as a risk factor for the development of HBS still remains controversial; younger age at the time of surgery as a risk factor for HBS has been reported previously, ${ }^{5,12,14}$ but other studies have stated that older patients are at higher risk for the development of HBS. ${ }^{20,25}$ Our data suggest that younger patients should be monitored more closely; however, explanations as to why younger patients are at a higher risk for HBS are still missing. On the other hand, in patients with primary hyperparathyroidism, advanced age has been associated with postoperative hypocalcemia. ${ }^{20,23,24}$ These studies suggested that vitamin D deficiency and poorer nutritional intake in older patients promote a higher risk for the development of HBS. At this time point, it still remains unclear why younger age constitutes a risk factor for the development of HBS. It could be hypothesized that the increases in bone formation and osteoblasts after parathyroidectomy are more pronounced in younger versus older patients. Additional larger studies need to be conducted to support this finding.

Analogous with the study by Goldfarb et al, ${ }^{14}$ and in contrast to previous studies, ${ }^{12,25}$ neither phosphate, PTH, hemoglobin, or urea levels preoperatively, nor the duration of renal replacement therapy were significant predictors of HBS in our study. In addition, we could identify lower preoperative calcium levels as a significant predictor of HBS, which was recently reported in a study from Torer et al, ${ }^{1}$ including 36 patients who were receiving hemodialysis.

Furthermore, we investigated the role of preoperative vitamin $\mathrm{D}$ therapy on postoperative serum calcium levels, the duration of intravenous vitamin D supplementation, and the incidence of HBS. Regarding the risk for HBS, no differences were observed between patients who received vitamin D preoperatively compared with patients who were not treated with vitamin D before surgery. No differences could be detected between serum calcium levels in the HBS group with vitamin D therapy before surgery compared with the HBS group without vitamin $\mathrm{D}$, and preoperative vitamin $\mathrm{D}$ therapy showed no differences on the duration of intravenous calcium supplementation. Our data provide no explanation for the recommendation of preoperative use of vitamin D to avoid HBS. ${ }^{21}$

We also investigated whether there was a decrease in prescriptions of the most common antihypertensive drugs (angiotensin-converting enzyme inhibitors, angiotensin 2 receptor antagonists, beta-blockers, calcium antagonists, and diuretics) after parathyroidectomy. We could not detect statistically significant differences between preoperative and postoperative doses during long-term follow-up in our patient cohort. Some case series, ${ }^{26}$ as well as data from Kestenbaum et $\mathrm{al}^{27}$ have reported significant decreases in blood pressure in patients after parathyroidectomy.

It is noteworthy that none of the included patients in our study was treated with calcimimetics before surgery. Whether the use of calcimimetics before surgery had affected the rates of HBS needs to be elucidated.

\section{Study limitations}

We acknowledge that our study had several limitations, which are mainly related to its retrospective nature. The major strengths of this study were the number of included patients, the detailed analysis of preoperative medications, and the investigation of many risk factors within a single patient cohort.

\section{Conclusion}

In conclusion, parathyroidectomy can be performed in patients with severe HPT with an acceptable outcome when medical therapy has failed. Postoperative hypocalcemia is a very common complication after parathyroidectomy. Younger patients and patients with low preoperative calcium levels are at higher risk for the development of HBS. It is noteworthy that minimal levels of calcium were detected 3 weeks after surgery, which underlines the importance of intensive "long-term" monitoring of patients up to 3 weeks after surgery. Preoperative vitamin D therapy could not prevent HBS and had no impact on the length of intravenous calcium supplementation.

\section{Disclosure}

The authors report no conflicts of interest in this work.

\section{References}

1. Torer N, Torun D, Torer N, et al. Predictors of early postoperative hypocalcemia in hemodialysis patients with secondary hyperparathyroidism. Transplant Proc. 2009;41(9):3642-3646.

2. Cheng SP, Liu CL, Chen HH, Lee JJ, Liu TP, Yang TL. Prolonged hospital stay after parathyroidectomy for secondary hyperparathyroidism. World J Surg. 2009;33(1):72-79.

3. Goodman WG. Recent developments in the management of secondary hyperparathyroidism. Kidney Int. 2001;59(3):1187-1201.

4. National Kidney Foundation. K/DOQI clinical practice guidelines for chronic kidney disease: evaluation, classification, and stratification. $\mathrm{Am}$ J Kidney Dis. 2002;39(2 Suppl 1):S1-S266.

5. Mittendorf EA, Merlino JI, McHenry CR. Post-parathyroidectomy hypocalcemia: incidence, risk factors, and management. Am Surg. 2004;70(2):114-119; discussion 119-120. 
6. Foley RN, Li S, Liu J, Gilbertson DT, Chen SC, Collins AJ. The fall and rise of parathyroidectomy in US hemodialysis patients, 1992 to 2002. J Am Soc Nephrol. 2005;16(1):210-218.

7. Malberti F, Marcelli D, Conte F, Limido A, Spotti D, Locatelli F. Parathyroidectomy in patients on renal replacement therapy: an epidemiologic study. J Am Soc Nephrol. 2001;12(6):1242-1248.

8. Cunningham J, Danese M, Olson K, Klassen P, Chertow GM. Effects of the calcimimetic cinacalcet $\mathrm{HCl}$ on cardiovascular disease, fracture, and health-related quality of life in secondary hyperparathyroidism. Kidney Int. 2005;68(4):1793-1800.

9. Kestenbaum B, Seliger SL, Gillen DL, et al. Parathyroidectomy rates among United States dialysis patients: 1990-1999. Kidney Int. 2004;65(1):282-288.

10. Locatelli F, Cannata-Andía JB, Drüeke TB, et al. Management of disturbances of calcium and phosphate metabolism in chronic renal insufficiency, with emphasis on the control of hyperphosphataemia. Nephrol Dial Transplant. 2002;17(5):723-731.

11. Jofré R, López Góméz JM, Menárguez J, et al. Parathyroidectomy: whom and when? Kidney Int Suppl. 2003;(85):S97-S100.

12. Viaene L, Evenepoel P, Bammens B, Claes K, Kuypers D, Vanrenterghem Y. Calcium requirements after parathyroidectomy in patients with refractory secondary hyperparathyroidism. Nephron Clin Pract. 2008;110(2):c80-c85.

13. Strickland PL, Recabaren J. Are preoperative serum calcium, parathyroid hormone, and adenoma weight predictive of postoperative hypocalcemia? Am Surg. 2002;68(12):1080-1082.

14. Goldfarb M, Gondek SS, Lim SM, Farra JC, Nose V, Lew JI. Postoperative hungry bone syndrome in patients with secondary hyperparathyroidism of renal origin. World J Surg. 2012;36(6):1314-1319.

15. Shih ML, Duh QY, Hsieh CB, et al. Total parathyroidectomy without autotransplantation for secondary hyperparathyroidism. World J Surg. 2009;33(2):248-254.

16. Gasparri G, Camandona M, Abbona GC, et al. Secondary and tertiary hyperparathyroidism: causes of recurrent disease after 446 parathyroidectomies. Ann Surg. 2001;233(1):65-69.
17. Cattan P, Halimi B, Aïdan K, et al. Reoperation for secondary uremic hyperparathyroidism: are technical difficulties influenced by initial surgical procedure? Surgery. 2000;127(5):562-565.

18. Rothmund M, Wagner PK, Schark C. Subtotal parathyroidectomy versus total parathyroidectomy and autotransplantation in secondary hyperparathyroidism: a randomized trial. World J Surg. 1991;15(6): 745-750.

19. Gagné ER, Ureña P, Leite-Silva S, et al. Short- and long-term efficacy of total parathyroidectomy with immediate autografting compared with subtotal parathyroidectomy in hemodialysis patients. J Am Soc Nephrol. 1992;3(4):1008-1017.

20. Brasier AR, Nussbaum SR. Hungry bone syndrome: clinical and biochemical predictors of its occurrence after parathyroid surgery. Am J Med. 1988;84(4):654-660.

21. Cruz DN, Perazella MA. Biochemical aberrations in a dialysis patient following parathyroidectomy. Am J Kidney Dis. 1997;29(5):759-762.

22. Mazzaferro S, Chicca S, Pasquali M, et al. Changes in bone turnover after parathyroidectomy in dialysis patients: role of calcitriol administration. Nephrol Dial Transplant. 2000;15(6):877-882.

23. Farese S. The hungry bone syndrome - an update. Ther Umsch. 2007;64(5):277-280. German [with English abstract].

24. Erbil Y, Bozbora A, Ozbey N, et al. Predictive value of age and serum parathormone and vitamin $\mathrm{d} 3$ levels for postoperative hypocalcemia after total thyroidectomy for nontoxic multinodular goiter. Arch Surg. 2007;142(12):1182-1187.

25. ErbilY, Barbaros U, Temel B, et al. The impact of age, vitamin D(3) level, and incidental parathyroidectomy on postoperative hypocalcemia after total or near total thyroidectomy. Am J Surg. 2009;197(4): 439-446.

26. Goldsmith DJ, Covic AA, Venning MC, Ackrill P. Blood pressure reduction after parathyroidectomy for secondary hyperparathyroidism: further evidence implicating calcium homeostasis in blood pressure regulation. Am J Kidney Dis. 1996;27(6):819-825.

27. Kestenbaum B, Andress DL, Schwartz SM, et al. Survival following parathyroidectomy among United States dialysis patients. Kidney Int. 2004;66(5):2010-2016.

\section{Publish your work in this journal}

The International Journal of Nephrology and Renovascular Disease is an international, peer-reviewed open-access journal focusing on the pathophysiology of the kidney and vascular supply. Epidemiology, screening, diagnosis, and treatment interventions are covered as well as basic science, biochemical and immunological studies. The journal welcomes

\section{Dovepress}

original research, clinical studies, reviews \& evaluations, expert opinion and commentary, case reports and extended reports. The manuscript management system is completely online and includes a very quick and fair peerreview system, which is all easy to use. Visit http://www.dovepress.com/ testimonials.php to read real quotes from published authors. 